Research Article

\title{
Forecasting Carbon Emissions with Dynamic Model Averaging Approach: Time-Varying Evidence from China
}

\author{
Siqi Xu $\mathbb{D}^{1},{ }^{1}$ Yifeng Zhang $\mathbb{D}^{2}{ }^{2}$ and Xiaodan Chen $\mathbb{D}^{2}$ \\ ${ }^{1}$ School of Social Development, Xihua University, Chengdu, China \\ ${ }^{2}$ School of Finance, Yunnan University of Finance and Economics, Kunming, China \\ Correspondence should be addressed to Yifeng Zhang; zyf@ynufe.edu.cn
}

Received 22 September 2020; Revised 9 October 2020; Accepted 10 October 2020; Published 28 October 2020

Academic Editor: Dehua Shen

Copyright $\odot 2020$ Siqi Xu et al. This is an open access article distributed under the Creative Commons Attribution License, which permits unrestricted use, distribution, and reproduction in any medium, provided the original work is properly cited.

\begin{abstract}
Although energy-related factors, such as energy intensity and energy consumption, are well recognized as major drivers of carbon dioxide emission in China, little is known about the time-varying impacts of other macrolevel nonenergy factors on carbon emission, especially those from macroeconomic, financial, household, and technology progress indicators in China. This paper contributes to the literature by investigating the time-varying predictive ability of 15 macrolevel indicators for China's carbon dioxide emission from 1982 to 2017 with a dynamic model averaging (DMA) method. The empirical results show that, firstly, the explanatory power of each nonenergy predictor changes significantly with time and no predictor has a stable positive/negative impact on China's carbon emissions throughout the whole sample period. Secondly, all these predictors present a distinct predictive ability for carbon emission in China. The proportion of industry production in GDP (IP) shows the greatest predictive power, while the proportion of FDI in GDP has the smallest forecasting ability. Interestingly, those Chinese household features, such as Engel's coefficient and household savings rate, play very important roles in the prediction of China's carbon emission. In addition, we find that IP are losing its predictive power in recent years, while the proportion of value-added of the service sector in GDP presents not only a leading forecasting weight, but a continuous increasing prediction power in recent years. Finally, the dynamic model averaging (DMA) method can produce the most accurate forecasts of carbon emission in China compared to other commonly used forecasting methods.
\end{abstract}

\section{Introduction}

As an important part of the atmosphere, greenhouse gases, i.e., carbon dioxide $\left(\mathrm{CO}_{2}\right)$, nitrous oxide, and methane, act just like a blanket, can absorb infrared radiation, and prevent it from escaping into outer space, maintaining the temperature of Earth's atmosphere and surface. However, since the beginning of the Industrial Revolution in the early 1800 s, the concentration of greenhouse gases, especially $\mathrm{CO}_{2}$, in the atmosphere, has greatly increased because of the great consumptions of fossil fuels. The level of $\mathrm{CO}_{2}$ in the atmosphere has increased by more than 40 percent, from about 280 parts per million (ppm) in the 1800 s to $400 \mathrm{ppm}$ recently. The increase in $\mathrm{CO}_{2}$ causes the gradual warming of the Earth's atmosphere and surface, which is known as global warming. The process of global warming would cause serious natural and societal effects such as extreme weather events, a rise in sea levels, and increasing ocean acidification.

In addition, China has become the largest $\mathrm{CO}_{2}$ emissions country in the world, by the end of 2019 , with a share as much as $28.8 \%$ of the total amount [1]. Thus, determining the major factors that would have an effect on the growth rate of China's carbon emissions is a key task for policymakers. Our research contributes to the literature on this issue in the following three points.

Firstly, many research studies have proved the impacts of energy-related factors, such as energy consumption per capita, total energy consumption, fossil fuel energy consumption, renewable energy consumption, nuclear energy consumption, and coal consumption, on $\mathrm{CO}_{2}$ emission (see [2-9] and among many others). This paper, however, pays attention to those nonenergy indicators from 
macroeconomy (especially from finance sectors), household wealth conditions, and technical progress level, which have not been investigated in a comprehensive framework in previous research studies. More specifically, the Chinese household features, such as household wealth or saving (consumption) behaviors, have not been investigated regarding their impacts on China's $\mathrm{CO}_{2}$ emission in the previous literature. In addition, patent number is commonly used as a proxy of technical progress in extant research studies. However, these patent data are not available for China in the early 1980s. Therefore, in our research, we use the ratios of total R\&D to GDP as well as the number of college students to China's population as the other two proxies to measure the technical progress condition in China.

Secondly, in terms of research methods, constant coefficient (CC) models, i.e., multivariate linear regression, cointegration, VECM, or ARDL, which have the advantages of providing simple and easy estimates, are widely used for investigating the impacts of different factors on the Chinese $\mathrm{CO}_{2}$ emission. It is, however, well documented in economic and econometric researches that $\mathrm{CC}$ models have the obvious shortcoming that they cannot depict the time-varying effects of one variable on another. It is also well known that major policy switching, business cycle, and economy certainty may alter the dependence structure between $\mathrm{CO}_{2}$ emission and its influential factors. Thus, it is very important and necessary to account for these time-varying effects by using models with time-varying parameter (TVP) setting. The TVP method is useful for exploring the time-varying connections between the explanatory variable and the explained variable because it can produce the time-varying parameters for explanatory variables. Thus, we utilize both traditional CC and TVP OLS models to forecast China's $\mathrm{CO}_{2}$ emission in recent years and evaluate their performances within several evaluation criteria.

Lastly, many recent research studies use a large number of factors to detect their impacts on China's $\mathrm{CO}_{2}$ emission (see $[10,11]$ and among many others). But using too many explanatory variables in an econometric model, no matter it is a CC or TVP model has some clear drawbacks. Koop and Korobilis [12] indicate that a model with too many explanatory variables often leads to overfitting in-sample and, thus, forecasting poorly out-of-sample. Besides, studies have shown that a fixed set of explanatory variables may not always be related to the explained variable throughout a long time period [3, 13-18]. In other words, during different time periods and/or under different policy conditions, the influence of each determinant on China's $\mathrm{CO}_{2}$ emission may not be fixed. Research studies further indicate that a model with the fixed set of predictors may behave inconsistently over time [19-21]. These problems can be solved by performing a dynamic model selection process at each time point, while the computational burden of this process is huge. In the process of dynamic model selection, if $n$ predictors are given, we need to evaluate $2 n$ models at each time point, so throughout the evaluation period of $T$, the total number of models to be assessed will be as large as $2 n T$. This computational task would be difficult to achieve when $n$ and
T are large. Therefore, the model averaging method, such as Bayesian model averaging (BMA) and forecast combination, is a preferred choice for improving the forecasting accuracy. Model averaging method is useful for achieving stable and accurate forecasts. However, either forecast combination or BMA method is difficult to capture each model's timevarying contribution because the weights they assigned for combining different models are fixed over time [19, 21, 22]. To address these problems, we further utilize a dynamic model averaging (DMA) method, which is proposed by Raftery et al. [23] and widely employed in recent researches [24-27], to carry out our task of forecasting China's $\mathrm{CO}_{2}$ emission with many predictors. Using two forgetting factors, DMA combines different models in a dynamic way, allowing the coefficients of predictors and the sets of predictors to change over time. These two forecasting factors can also simplify the model selection process which has a huge computational task.

The remainder of this paper is organized as follows: Section 2 reviews the extant literature on the topic of impactors on China's carbon emission. Section 3 describes the data used in this paper. Methodologies are introduced in Section 4. Section 5 analyzes the empirical results and Section 6 concludes the paper.

\section{Literature Review}

Numerous studies have been trying to investigate the factors that would influence $\mathrm{CO}_{2}$ emissions. Various variables, such as population activities, energy consumption patterns, economic growth, innovation and technology, urbanization process, and government policies, are used in these studies to explain their effects on carbon emissions. These impact factors can be summarized into three major categories.

Firstly, energy consumption is an output of human activities that produces carbon emission. From this perspective, population growth, population density, and urbanization process in an economy are supposed to play significant roles in carbon dioxide emissions. Zhang and Tan [28] investigate the connections between $\mathrm{CO}_{2}$ emissions and population factors using the Stochastic Impacts by Regression on Population, Affluence, and Technology (STIRPAT) method. They found a positive connection between carbon emissions and population. STIRPAT method is also adopted by Guan et al. [29] to discuss the main drivers of China's $\mathrm{CO}_{2}$ emissions. According to their results, $\mathrm{CO}_{2}$ emission is negatively correlated with disposable income, population density, and development of tertiary industries, whereas positively correlated with GDP per capita, secondary industries, and urban employment. Employing four Chinese megacities (Beijing, Tianjin, Shanghai, and Chongqing) as cases, Shi et al. [30] conclude that the improvement of resident living standards and the development of manufacturing in these cities are the main drivers of carbon emission per capita from 2010 to 2015 . Yao et al. [31] use the mediating effect model and the threshold regression model, finding that the urbanization in China helps to decline the carbon emission scale, carbon intensity, and carbon emission per capita in recent years. Based on the data 
of consumption level, population size, and population structure in China from 1978 to 2008, Zhu and Peng [32] use the ridge regression method and find that the urbanization of population is the key driver for the growth of China's $\mathrm{CO}_{2}$ emission. Moreover, population structure, population age, urbanization, and household size are also significantly associated with carbon emissions. Ma et al. [33] further note that wealth, economic structure, energy structure, population structure, and the development of technology are also major influential factors of China's carbon emission. Meng et al. [34] investigate the impact of local officials' promotion incentives on China's $\mathrm{CO}_{2}$ emission. The results indicated the significant influence of age, tenure, and local officials' promotion sources on total $\mathrm{CO}_{2}$ emissions.

Secondly, economic growth is regarded as another major driver of excessive energy consumption in China $[28,29,35]$. It is agreed that there are significant positive connections among China's $\mathrm{CO}_{2}$ emission and economic growth and energy consumption. Based on China's energy consumption data from 2005 to 2016, Ma et al. [36] find that aggressive economic output and increasing energy consumption basically promote China's carbon emissions. More specifically, $\mathrm{CO}_{2}$ emissions from China's energy consumption mainly come from industry, residential consumption sector, transportation industry, and tertiary industry. Using the structural decomposition analysis (SDA) approach, Chen et al. [37] measure the construction industry $\mathrm{CO}_{2}$ emissions difference between the USA and China by the structural decomposition analysis (SDA) and found that the four largest contributors to the difference of China and USA construction carbon emissions are energy intensity, final demand ration effect, final demand effect, and the carbonization factor effect. These findings suggest the adverse interaction between construction carbon emissions and economic growth. Thus, they propose that the Chinese government should take efforts to change the economic development mode. By formulating the industrial subsector decomposition analysis in Tianjin province, China, Kang et al. [38] find that the economic growth is the most important influential factor for driving the growth of $\mathrm{CO}_{2}$ emissions, while energy efficiency improvement is crucial to promote the decreases of $\mathrm{CO}_{2}$ emissions. By using the LMDI method, Wang and Yang [39] show that the main influential factors for the industrial $\mathrm{CO}_{2}$ emissions in Beijing-Tianjing-Hebei economic band including the rapid economic growth, energy structure, and energy intensity. Ma et al. [40] also employ the LMDI method to examine the connection between economic growth and household $\mathrm{CO}_{2}$ emissions in China. Their results show that energy intensity and economic growth are the two primary drivers of carbon emission fluctuations. By using the DPSIR and PLS-SEM methods, Wei et al. [35] find that the economic development level and the urbanization are the two main drivers for $\mathrm{CO}_{2}$ emissions. In summary, sustainable economic growth and long-term industrial transformation would lead to the continued growing for the total $\mathrm{CO}_{2}$ emissions [41].

Lastly, financing activities can adjust the economic structure and improve economic efficiency, since finance sector is generally considered to be of low resource consumption and high value-added. So many researchers suggest that improving finance sector is an effective way to reduce carbon dioxide intensity. Jalil and Feridun [42] explore the influence of energy consumption, economic growth, and financial development on China's $\mathrm{CO}_{2}$ emissions from 1953 to 2006 and prove that a decrease in carbon emissions can be caused by financial development. Other empirical analysis also confirms that the development of tertiary industries, including finance sector development, is the key influential factor for $\mathrm{CO}_{2}$ emission decreases $[29,43]$. By applying spatial econometric analysis, Xu et al. [44] reach a conclusion that China's financial structure is negatively related to the carbon emission, meaning that optimizing financial structure is an effective strategy for reducing $\mathrm{CO}_{2}$ emissions. The research of Zhang et al. [45] shows that carbon emission trading (CET) market, which is one of the promising financial market, has a significant impact on the decrease of China's $\mathrm{CO}_{2}$ emissions in recent years. This conclusion is consistent with Zhou et al. [46] but quite different from the study of Mo et al. [47], which reveals that China's carbon emissions trading program cannot support low carbon energy consumption, and other policies are necessary to complete China's CET trading mechanism. Except for the factors listed above, foreign direct investment (FDI) is another significant contributor to carbon emission reduction [31,48,49], implying that financial development can attract more FDI inflow and evolve superior technology to reduce carbon emission [50]. However, other researchers debate that due to economy globalization, financing activities are conducive to the expansion of industrialization, which may bring more FDI, faster economic growth, and thus larger $\mathrm{CO}_{2}$ emissions [51-54]. Recently, the results of [36] show that China's tertiary industries account for an increasing proportion of energy consumption. Using the Granger causality test and ARDL bound test, Zhang and Zhang [11] investigate the short-term and long-term dynamic and casual relationship between China's $\mathrm{CO}_{2}$ emissions and GDP, exchange rate, FDI, and trade structure from 1982 to 2016. They find the negative effects of the exchange rate and the trade in services on China's carbon emissions and the positive impact of FDI inflows on it. These results come to a consensus with Zhang [55], indicating that the financial industry in China is an important factor for promoting $\mathrm{CO}_{2}$ emissions. Zhang [55] examines the impact of China's financial development on $\mathrm{CO}_{2}$ emissions by various econometric techniques, including the Granger causality test, cointegration test, and variance decomposition. The empirical results show that the financial development of China, especially the financial intermediation scale, is an important influential factor for the increase of $\mathrm{CO}_{2}$ emissions. In addition, even though the results show that FDI has the least impact on $\mathrm{CO}_{2}$ emission in China among the concerned financial development indicators because it only accounts for a small proportion in the GDP of China (see also in [49]), Zhang [55] also insists that FDI is an important $\mathrm{CO}_{2}$ emission influential factor due to the utilization of China's FDI in carbon-intensive sectors. In summary, it can be seen from the above literature that financial sectors have 
important effects on carbon emission in China, but there are no widely accepted relationships between them.

\section{Data}

To account for both changes in China's carbon emission and total population, we use carbon emission per capita to measure the carbon emission levels in China (see also in $[11,45])$. Furthermore, as explained above, we do not focus on those predictors directly related to energy sectors, such as energy consumption per capita, total energy consumption, fossil fuel energy consumption, renewable energy consumption, nuclear energy consumption, and coal consumption. In contrast, we utilize 15 indicators from three nonenergy categories: (1) China's macroeconomic indices, especially those from financial sectors (see $[11,45,55]$ and among many others). (2) Indicators on China's household wealth conditions and saving behaviors: we think that these indicators are key bases for a family to decide what kinds of energy and how much energy it will consume within a time period, which will influence the carbon emissions in China consequently. (3) Technical progress indices: as documented in many studies $[10,35]$, technology development can not only improve the energy production and consumption with lower carbon emission but also promote better methods for energy conservation and environment protection. To account for both data available and data matching, we collect the data we need covering a time period from 1982 to 2017. All data are recorded in annual frequency with 36 observations for each of them. Table 1 presents the detailed definitions of these indicators.

Table 1 reveals that the 15 nonenergy predictors are selected from three general categories: macroeconomic, household feature, and technical progress indicators. In addition, macroeconomic indicators are further divided into four specific sorts from macroeconomic aggregate, macroeconomic structure, financial market, and international trade. Table 2 then shows the descriptive statistics for these variables.

To ensure stationary, all data are transformed in the forms of natural logarithm growth rate, which is a method commonly used in time series analysis. Table 2 indicates that the growth rates vary greatly among them, indicating some interesting macroeconomic overviews in China. For example, firstly, in terms of macroeconomic structure, the proportions of both agriculture and industry productions to GDP of China have negative means, but the share of valueadded of the service sector in the GDP keeps a positive mean of 2.4 percent. That is to say, the service sector in GDP is becoming more and more important in determining the GDP growth of China. However, the industry and agriculture sectors are losing this power. Additionally, we can also see that the Chinese public finance revenue maintains a negative 0.2 percent annual growth rate, and the public expenditure, however, keeps a positive 0.2 percent growth rate. These two numbers further reveal that the Chinese government is trying to lower down the tax and other financial burdens in the real economy and increase the public welfare in the past few decades. Secondly, as far as the
Chinese household features are concerned, we find that Engel's coefficient continues to decrease, while the saving rate is increasing, which together imply that the Chinese family is becoming more and more affluent with more money being saved since 1982. Finally, with regard to the technical progress indices, we can see that both $\mathrm{R} \& \mathrm{D}$ and college students keep a positive growth rate in China, indicating the continuous improvement in the innovation capabilities and scientific research strength in China.

In addition, we find that almost all the variables are skewed distributed with excess kurtosis. Considering this, most of the variables reject the null hypotheses of normality distribution based on the Jarque-Bera statistics. However, most results in Ljung-Box $Q$ test indicate no rejections for the null hypotheses of no autocorrelation up to 5th lag order. The most important results are that all the variables considered here reject the null hypotheses of one unit root according to the ADF and/or P-P statistics, implying that all the time series are stationary and can be modeled directly without further transforms.

\section{Methodology}

4.1. TVP Model and Dynamic Model Averaging (DMA) Forecasts. Although the constant coefficient (CC) models such as autoregression (AR) or multivariable regression have the advantages of providing simple estimation and straightforward explanations, they also possess the drawbacks that the regressor coefficients of the CC model are fixed. In contrast, the time-varying parameter (TVP) approach is a very natural way to depict the time-varying relationships between explanatory variables and explained variable because it allows the parameters of explanatory variables to be time-varying. As mentioned by Primiceri [56], Koop et al. [57], and Wei and Cao [24], a basic TVP model can be defined as follows:

$$
\begin{aligned}
& y_{t}=x_{t-1}^{\prime} \beta_{t}+\varepsilon_{t}, \\
& \beta_{t}=\beta_{t-1}+\eta_{t},
\end{aligned}
$$

where $y_{t}$ is the target variable to be forecasted at time $t . x_{t-1}$ is a $1 \times m$ vector of predictors, in which the lagged dependent variable $y_{t}$ is usually included besides other exogenous variables. $\beta_{t}$ is an $m \times 1$ vector of coefficients, $\varepsilon_{t} \sim$ i.i.d. $N\left(0, V_{t}\right)$, and $\eta_{t} \sim$ i.i.d. $N\left(0, W_{t}\right)$.

For the TVP model defined in equations (1) and (2), the predictors in $x_{t-1}$ are assumed to be fixed throughout the whole forecasting time period, which may cause the overparameterization problem and a loss of forecasting precision. However, the dynamic model averaging (DMA) and dynamic model selection (DMS) can facilitate the problem of the TVP model because they allow both the predictor sets (forecasting models) and the coefficients of predictors to be time-varying. Therefore, following Raftery et al. [23], Koop and Korobilis [12], Wei and Cao [24], and Wei et al., [25], we utilize DMA and DMS methods to forecast China's carbon emission. The DMA (DMS) method can be written as follows: 
TABLE 1: Definitions of the explained variable and various nonenergy predictors.

\begin{tabular}{|c|c|c|c|c|}
\hline Category (frequency) & Variable & Definition & Calculation & Unit \\
\hline \multirow{2}{*}{$\begin{array}{l}\text { Explained variable } \\
\text { (annual) } \\
\text { Predictors (annual) } \\
\text { Macroeconomic } \\
\text { aggregate }\end{array}$} & Carbon & $\mathrm{CO}_{2}$ emission per capita & $\begin{array}{l}\text { Total } \mathrm{CO}_{2} \text { emission divided by the total } \\
\text { population in China }\end{array}$ & $\begin{array}{l}\text { Tons per } \\
\text { capita }\end{array}$ \\
\hline & GDP & Nominal GDP per capita & $\begin{array}{l}\text { Nominal GDP divided by the total } \\
\text { population in China }\end{array}$ & $\begin{array}{c}\text { Yuan per } \\
\text { capita }\end{array}$ \\
\hline \multirow{3}{*}{$\begin{array}{l}\text { Macroeconomic } \\
\text { structure }\end{array}$} & Agriculture & $\begin{array}{c}\text { Proportion of agriculture production to } \\
\text { total GDP }\end{array}$ & $\begin{array}{c}\text { Agriculture production divided by GDP } \\
\text { in China }\end{array}$ & $\%$ \\
\hline & Industry & $\begin{array}{l}\text { Proportion of industry production to total } \\
\text { GDP }\end{array}$ & $\begin{array}{l}\text { Industry production divided by total } \\
\text { GDP in China }\end{array}$ & $\%$ \\
\hline & Service added & $\begin{array}{l}\text { Proportion of value-added of the service } \\
\text { sector to total GDP }\end{array}$ & $\begin{array}{l}\text { Value-added of the service sector } \\
\text { divided by GDP in China }\end{array}$ & $\%$ \\
\hline \multirow{5}{*}{ Financial market } & FDI & $\begin{array}{c}\text { Proportion of foreign direct investment in } \\
\text { China to total GDP }\end{array}$ & FDI divided by GDP in China & $\%$ \\
\hline & Total loan & $\begin{array}{l}\text { Proportion of total loan by financial } \\
\text { intermediation in China to total GDP }\end{array}$ & Total loan divided by GDP in China & $\%$ \\
\hline & Public revenue & $\begin{array}{c}\text { Proportion of total public revenue in China } \\
\text { to total GDP }\end{array}$ & $\begin{array}{l}\text { Total public revenue divided by GDP in } \\
\text { China }\end{array}$ & $\%$ \\
\hline & $\begin{array}{c}\text { Public } \\
\text { expenditure }\end{array}$ & $\begin{array}{c}\text { Proportion of total public expenditure in } \\
\text { China to total GDP }\end{array}$ & $\begin{array}{l}\text { Total public expenditure divided by total } \\
\text { GDP }\end{array}$ & $\%$ \\
\hline & $M_{0}$ & Proportion of $M_{0}$ in China to total GDP & $M_{0}$ divided by GDP in China & $\%$ \\
\hline \multirow{2}{*}{ International trade } & Exchange rate & The exchange rate of RMB against US dollar & $\begin{array}{c}\text { Nominal exchange rate of RMB against } \\
\text { US dollar }\end{array}$ & $\begin{array}{l}\text { Yuan/ } \\
\text { dollar }\end{array}$ \\
\hline & Service trade & $\begin{array}{l}\text { Proportion of service trade to total trade in } \\
\text { China }\end{array}$ & $\begin{array}{l}\text { Service trade divided by total } \\
\text { international trade in China }\end{array}$ & $\%$ \\
\hline \multirow[t]{2}{*}{ Household feature } & $\begin{array}{l}\text { Engel's } \\
\text { coefficient }\end{array}$ & Proportion of income spent on food & $\begin{array}{l}\text { Food expenditure of China’s family } \\
\text { divided by family's income }\end{array}$ & $\%$ \\
\hline & Total saving & Proportion of family saving to GDP & China's family saving divided by GDP & $\%$ \\
\hline \multirow{2}{*}{ Technical progress } & $\mathrm{R} \& \mathrm{D}$ & $\begin{array}{l}\text { Proportion of total research \& development } \\
\text { (R\&D) expenditure to GDP in China }\end{array}$ & $\begin{array}{l}\text { Total research \& development (R\&D) } \\
\text { expenditure divided by GDP in China }\end{array}$ & $\%$ \\
\hline & $\begin{array}{l}\text { College } \\
\text { student }\end{array}$ & $\begin{array}{c}\text { Proportion of college student number to } \\
\text { population in China }\end{array}$ & $\begin{array}{l}\text { College student number divided by total } \\
\text { population in China }\end{array}$ & $\%$ \\
\hline
\end{tabular}

TABLE 2: Descriptive statistics for energy returns.

\begin{tabular}{|c|c|c|c|c|c|c|c|c|}
\hline & Mean & St. deviation & Skewness & Kurtosis & Jarque-Bera & $Q(5)$ & $\mathrm{ADF}$ & $\mathrm{P}-\mathrm{P}$ \\
\hline Carbon & 0.043 & 0.043 & $1.138^{* * *}$ & $1.518^{*}$ & $10.910^{* * *}$ & $31.304^{* * *}$ & $-2.998^{* *}$ & $-2.958^{* *}$ \\
\hline GDP & 0.135 & 0.060 & $0.843^{*}$ & 0.327 & 4.299 & $26.065^{* * *}$ & $-3.257^{* *}$ & $-2.867^{*}$ \\
\hline Agriculture & -0.041 & 0.044 & 0.299 & 0.581 & 1.013 & 5.622 & $-5.405^{* * *}$ & $-5.208^{* * *}$ \\
\hline Industry & -0.003 & 0.023 & 0.632 & $1.521^{*}$ & $5.708^{*}$ & 7.783 & $-3.741^{* * *}$ & $-3.738^{* * *}$ \\
\hline Service added & 0.024 & 0.033 & $1.336^{* * *}$ & $3.510^{* * *}$ & $28.374^{* * *}$ & 7.828 & $-3.965^{* * *}$ & $-3.990^{* * *}$ \\
\hline FDI & 0.021 & 0.221 & $2.254^{* * *}$ & $4.726^{* * *}$ & $62.208^{* * *}$ & 7.876 & $-5.487^{* * *}$ & $-4.507^{* * *}$ \\
\hline Total loan & 0.017 & 0.108 & $-2.173^{* * *}$ & $9.359^{* * *}$ & $155.310^{* * *}$ & 3.502 & $-2.625^{*}$ & $-6.299^{* * *}$ \\
\hline Public revenue & -0.002 & 0.062 & $-0.794^{*}$ & 0.130 & 3.701 & 39.392 & $-2.692^{*}$ & $-2.599^{*}$ \\
\hline Public expenditure & 0.002 & 0.065 & -0.156 & -0.156 & 0.177 & 27.427 & $-2.618^{*}$ & $-2.628^{*}$ \\
\hline$M_{0}$ & 0.001 & 0.073 & $0.821^{*}$ & 1.457 & $7.024^{* *}$ & 8.349 & $-4.102^{* * *}$ & $-4.040^{* * *}$ \\
\hline Exchange rate & 0.036 & 0.097 & $2.172^{* * *}$ & $5.338^{* * *}$ & $69.084^{* * *}$ & $16.384^{* * *}$ & $-5.047^{* * *}$ & $-4.219^{* * *}$ \\
\hline Service trade & 0.012 & 0.109 & -0.516 & $1.831^{* *}$ & $6.443^{* *}$ & 6.985 & $-2.625^{*}$ & $-5.967^{* * *}$ \\
\hline Engel's coefficient & -0.020 & 0.036 & $-0.824^{*}$ & $3.051^{* * *}$ & $17.539^{* * *}$ & 1.974 & $-4.148^{* * *}$ & $-5.500^{* * *}$ \\
\hline Total saving & 0.008 & 0.037 & 0.231 & -0.258 & 0.410 & 7.547 & $-2.399^{*}$ & $-3.925^{* * *}$ \\
\hline $\mathrm{R} \& \mathrm{D}$ & 0.016 & 0.105 & $1.163^{* * *}$ & $3.965^{* * *}$ & $30.830^{* * *}$ & $14.908^{* *}$ & $-3.435^{* *}$ & $-3.516^{* *}$ \\
\hline College student & 0.081 & 0.080 & $1.053^{* *}$ & 0.357 & $6.652^{* *}$ & 36.586 & $-2.710^{*}$ & -2.110 \\
\hline
\end{tabular}

Notes: the Jarque-Bera statistic tests the null hypothesis of normal distribution. $Q(5)$ is the Ljung-Box statistics that test the null hypothesis of no serial correlation for up to 5 orders. ADF are the statistics of Augmented Dickey-Fuller unit root test. P-P refers to the statistics of Phillips-Perron unit root tests. Symbols ${ }^{* * *},{ }^{* *}$, and ${ }^{*}$ indicate the rejections of null hypothesis at $1 \%, 5 \%$, and $10 \%$ significance levels, respectively.

$$
\begin{aligned}
y_{t} & =x_{t-1}^{(k)^{\prime}} \beta_{t}^{(k)}+\varepsilon_{t}^{(k)}, \\
\beta_{t}^{(k)} & =\beta_{t-1}^{(k)}+\eta_{t}^{(k)},
\end{aligned}
$$

where $x_{t-1}^{(k)^{\prime}} \subseteq x_{t-1}^{\prime}$ for $k=1,2, \ldots, K$ indicates a set of predictors, $\varepsilon_{t} \sim$ i.i.d. $N\left(0, V_{t}^{(k)}\right)$, and $\eta_{t} \sim$ i.i.d. $N\left(0, W_{t}^{(k)}\right)$. For the set $x_{t-1}^{\prime}$ with $m$ predictors, there would be $K=2^{m}$ possible 
combinations of these predictors. The uncertain factors in these $K$ models can then be incorporated by DMA and DMS in a dynamic way:

$$
\begin{aligned}
\widehat{y}_{t}^{\mathrm{DMA}} & =\sum_{k=1}^{K} \pi_{(t \mid t-1, k)} x_{t-1}^{(k)^{\prime}} \beta_{t-1}^{(k)}, \\
\hat{y}_{t}^{\mathrm{DMS}} & =x_{t-1}^{\left(k^{*}\right)^{\prime}} \beta_{t-1}^{\left(k^{*}\right)},
\end{aligned}
$$

where $Y^{t-1}=\left\{y_{1}, \ldots, y_{t-1}\right\}, \pi_{(t \mid t-1, k)}=\operatorname{Pr}\left(L_{t}=k \mid Y^{t-1}\right)$ is the probability (or weight) assigned to model $k$, and the equation $L_{t}=k$ denotes that model $k$ is chosen at time $t$. DMA approach obtains its forecasts by averaging all the $K$ models in terms of their historical forecasting performances, calculated by the probability, $\pi_{(t \mid t-1, k)}$. However, DMS selects the model which has the highest probability, $\pi_{\left(t \mid t-1, k^{*}\right)}$.

The DMA and DMS methods discussed above have the drawback of heavy computational when the sample length is long or the number of predictors is large. So Raftery et al. [23] propose a Kalman filter method which involves two forgetting factors, $\lambda$ and $\alpha$, to simplify the estimation process without loss of forecast accuracy. $\lambda$, which is a forgetting factor with $0<\lambda \leq 1$, can simplify the covariance matrix of $\beta_{t-1}^{(k)}$, which is important for the calculation of $\beta_{t-1}^{(k)}$. This simplified process is given as follows:

$$
\begin{aligned}
& \beta_{t \mid t-1}^{(k)}=\beta_{t-1 \mid t-1}^{(k)}, \\
& \Sigma_{t \mid t-1}^{(k)}=\frac{1}{\lambda} \Sigma_{t-1 \mid t-1}^{(k)},
\end{aligned}
$$

where $\Sigma_{t \mid t-1}^{(k)}$ is the covariance matrix of $\beta_{t-1}^{(k)}$. Then, the parameter estimation is achieved by the following updating equations:

$$
\widehat{\beta}_{t \mid t}^{(k)}=\widehat{\beta}_{t-1 \mid t-1}^{(k)}+\Sigma_{t \mid t-1}^{(k)} x_{t-1}^{(k)^{\prime}}\left(V_{t}^{(k)}+x_{t-1}^{(k)^{\prime}} \Sigma_{t \mid t-1}^{(k)} x_{t-1}^{(k)}\right)^{-1}\left(y_{t}-x_{t-1}^{(k)} \hat{\beta}_{t-1}^{(k)}\right),
$$

$\Sigma_{t \mid t}^{(k)}=\Sigma_{t \mid t-1}^{(k)}-\Sigma_{t \mid t-1}^{(k)} x_{t-1}^{(k)^{\prime}}\left(V_{t}^{(k)}+x_{t-1}^{(k)^{\prime}} \Sigma_{t \mid t-1}^{(k)} x_{t-1}^{(k)}\right)^{-1} x_{t-1}^{(k)} \Sigma_{t \mid t-1}^{(k)}$.

For the probability, $\pi_{(t \mid t-1, k)}$, if a transition probability matrix is used, $K=2^{m}$ model combinations should be considered at each time in point. $m$ is the number of predictors, and if the sample period is long or $m$ is large, it is computationally infeasible to operate the Markov switching in the $K \times K$ matrix. However, the use of the forgetting factor, $\alpha(0<\alpha \leq 1)$, provides an effective way for reducing the calculation error and time. Based on this forgetting factor, the probability for the forecasting model $k$ is defined as follows:

$$
\pi_{(t \mid t-1, k)}=\frac{\pi_{(t-1 \mid t-1, k)}^{\alpha}}{\sum_{\ell=1}^{K} \pi_{(t-1 \mid t-1, \ell)}^{\alpha}}
$$

and the updating equation is defined as follows:

$$
\pi_{(t \mid t, k)}=\frac{\pi_{(t \mid t-1, k)} f_{k}\left(y_{t} \mid Y^{t-1}\right)}{\sum_{y_{t} \mid Y^{t-1}}^{K} \pi_{(t \mid t-1, k)} f_{\ell}\left(y_{t} \mid Y^{t-1}\right)},
$$

where $f_{\ell}\left(y_{t} \mid Y^{t-1}\right)$ is the predictive density of model $\ell$. In summary, the steps through equations (5)-(10) consist of a complete process of Kalman filter updating and prediction method. Furthermore, Raftery et al. [23] indicate that a BMA (Bayesian model averaging) method can be regarded as a special case of the DMA model with $\lambda=\alpha=1$.

4.2. Model Evaluation. Various statistical criteria can be used to quantitatively assess the forecasting performance of different models. Following the mainstream of literature in this field, two loss functions, mean squared forecast error (MSFE) and mean absolute forecast error (MAFE), are used in this paper. MSFE and MSAE are simply defined as follows:

$$
\begin{aligned}
& \text { MSFE }=M^{-1} \sum_{t=1}^{M}\left(y_{t}-\widehat{y}_{t}\right)^{2}, \\
& \text { MAFE }=M^{-1} \sum_{t=1}^{M}\left|y_{t}-\widehat{y}_{t}\right|,
\end{aligned}
$$

where $M$ is the total number of forecasting methods, $y_{t}$ denotes the true observation, and $\hat{y}_{t}$ is the forecast set achieved by different forecasting methods.

However, the two loss functions discussed above can hardly offer us the significance levels of forecasting difference among various models. Therefore, this paper utilizes the model confidence set (MCS) test which is proposed by Hansen et al. [58] and widely used in recent research studies $[24,25,59]$, to achieve this goal and to determine the superior models. The MCS test is developed from several traditional and standard model evaluation methods [60-63] but with more obvious advantages over these traditional ones. Firstly, the MCS test uses a bootstrap method to obtain the test statistics, reducing the influence of outliers in the data. Secondly, it does not have to specify a benchmark mode. Finally, this test does not limit the number of the "best" model to be one. The MCS process is as follows.

Suppose that we have a model set, $M_{0}=\left\{1, \ldots, m_{0}\right\}$ which includes a finite number of objects (models). These models are evaluated over the sample, $t=1, \ldots, n$, and under a loss function $i$. The purpose of MCS is to select a model set, $M^{*}$, which consists of the best models from $M_{0}$. The set of superior models can be defined as follows:

$$
M^{*} \equiv\left\{u \in M_{0}: E\left(d_{i, u v, t}\right) \leq 0, \quad \text { for all } v \in M_{0}\right\},
$$

where $d_{u v, t} \equiv L_{u, t}-L_{v, t}$ is the relative performance of model $u$ and model $v$, for any $u, v \in M_{0}$, in which $L_{u, t}$ is the loss of model $u$ in period $t$, and $E\left(d_{i, u v, t}\right)$ is the mathematical expectation of $d_{u v, t}$. MCS test is performed by a series of 
significance tests, in which the models that are found to be significantly worse than other elements of $M_{0}$ are eliminated. The null hypothesis of this test can be identified as follows:

$$
H_{0, M}: E\left(d_{i . u v, t}\right)=0, \quad \text { for all } u, v \in M \subset M_{0} .
$$

The MCS process consists of an equivalence test, $\delta_{M}$, and an elimination rule, $e_{M}$. $\delta_{M}$ examines the hypothesis $H_{0}$ for any two models in $M_{0}$. When $H_{0}$ is rejected, $e_{M}$ is used to identify the model that is to be removed from $M_{0}$. A model set, $\widehat{M}_{1-\alpha}^{*}$, which consists of the set of "surviving" models, and which are named as the MCS, can be obtained by repeating these two tests. The significance level, $\alpha$, of the MCS test is generally set to be 0.1 by Hansen et al. [58] and among many others. If the $p$ value of one MCS test is larger than 0.1, the corresponding model is a "surviving" model and it has the forecasting accuracy that is superior to other competitive models.

In the MCS test, two statistics, the range statistic $\left(T_{R}\right)$ and the semiquadratic statistic $\left(T_{S Q}\right)$, are commonly utilized. They are calculated as follows:

$$
\begin{gathered}
T_{R}=\max _{u, v \in M} \frac{\left|\bar{d}_{i, u v}\right|}{\sqrt{\operatorname{var}\left(d_{i, u v}\right)}}, \\
T_{S Q}=\max _{u, v \in M} \frac{\left(\bar{d}_{i, u v}\right)^{2}}{\operatorname{var}\left(\bar{d}_{i, u v}\right)},
\end{gathered}
$$

where $\bar{d}_{i, u v}=(1 / n) \sum_{t=1}^{n} d_{i, u v, t}$. The null hypothesis in equation (13) cannot be rejected when the $p$ values of $T_{R}$ and $T_{S Q}$ are larger than 0.1 . The asymptotic distributions of these two test statistics depend on nuisance parameters, so they are nonstandard. However, these conditions do not pose any obstacles because the distribution of these two statistics can be easily estimated by the bootstrap methods and thus implicitly solve the problem of nuisance parameter. To get more robust conclusions, except for $T_{R}$ and $T_{S Q}$, four more test statistics, i.e., $T_{\max }, T_{Q}, T_{F}$, and $T_{D}$, are used in our research. A more detailed discussion of these test statistics can be found in Hansen et al. [58].

\section{Empirical Results}

5.1. Time-Varying Contributions of Single Explanatory Variable to Carbon Emission. In this section, we firstly examine the time-varying effects of individual predictors on China's carbon emission by using the simple univariate TVP regression model denoted in equations (1) and (2). For clarity, Figure 1 represents the time-varying coefficients for only 9 predictors in the univariate TVP regression.

Figure 1 shows that the explanatory power of each predictor really changes significantly with time. In general, no predictors always have positive or negative impacts on carbon emissions in China throughout the estimation time period. For example, through 1985 to 1990, the proportion of industry production to GDP (IP) offers negative effects, while from 1991 to 2017 it has large positive impacts on China's carbon emission. GDP per capita has a positive impact on carbon emission in most years, but experiences an obvious decreasing explanatory power from 2004 and ends up with a small negative effect in 2017. Similar results can also be evidenced for other predictors in Figure 1. Moreover, we can see that the impacts of different predictors vary greatly with time. In particular, IP seems to provide the largest positive impact in recent years. The proportion of value-added of the service sector to total GDP (service added), however, has the largest negative effects on China's carbon emission from 2000.

In summary, it is interesting but difficult to quantify the overall contributions of various predictors on China's carbon emission in a time-varying way. The empirical findings in this section only give us the in-sample fitting results of time-varying effects of explanatory variables on carbon emission within a univariate TVP model. Thus, to obtain the out-of-sample forecasting evaluations, we have to seek helps from various forecasting results in multivariate TVP models and model combination methods.

5.2. Forecasting Results of Different Models. In the extant literature, to identify what factors are important for determining carbon emission in China is usually investigated by multivariate constant coefficient (CC) OLS regression models. Nevertheless, as discussed above, a better way to solve this problem is to seek help from TVP models. Furthermore, to take the different contributions of various explanatory variables at different time periods or market conditions into account, we further employ several commonly used combination forecasting approaches in this paper. In summary, nine models are considered here: CC OLS, TVP OLS, equal weighted, BMA, BMS, DMA95, DMS95, DMA99, and DMS99. The recursive out-of-sample forecasting approach is applied to all the nine models. The descriptions of these models in details are as follows:

(1) CC OLS: a constant coefficient multivariate regression model with all the 15 explanatory variables

(2) TVP OLS: a time-varying parameter multivariate regression model with all the 15 explanatory variables

(3) Equal weighted: the equal-weighted averaging of $K$ OLS models, i.e., the equal-weighted DMA model. In this paper, we have 15 explanatory variables, which means that we have $K=2^{15}=32,768$ models to combine

(4) BMA: DMA forecasting with $\lambda=\alpha=1$

(5) BMS: DMS forecasting with $\lambda=\alpha=1$

(6) DMA95: dynamic model averaging with $\lambda=\alpha=0.95$

(7) DMS95: dynamic model selection with $\lambda=\alpha=0.95$

(8) DMA95: dynamic model averaging with $\lambda=\alpha=0.99$

(9) DMS95: dynamic model selection with $\lambda=\alpha=0.99$

To get a visible overview of the performances for these forecasting models, Figure 2 shows the predictive results through 1985 to 2017. The blue line with circles denotes the true growth rate of carbon emission per capita in China, 


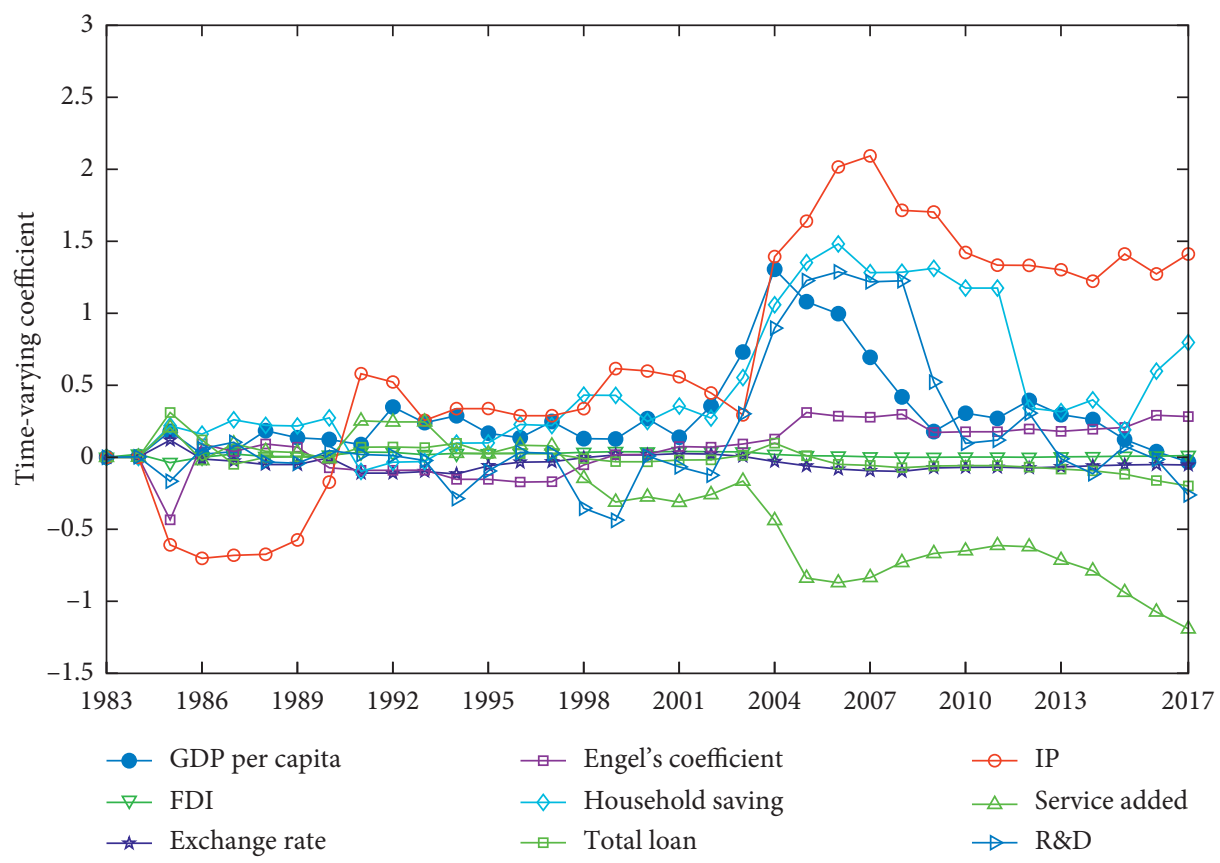

FIGURE 1: Estimations of time-varying coefficients of univariate TVP regression models.

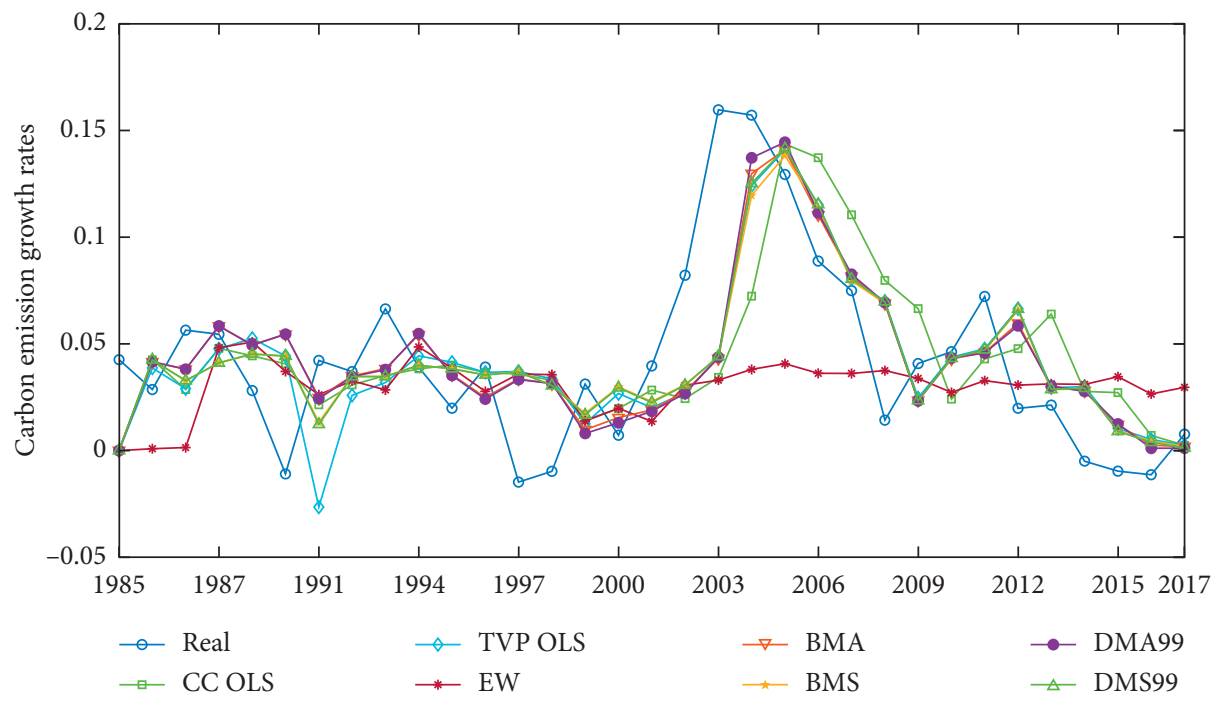

FIGURE 2: Carbon emission forecasting results by various models.

while other lines with different colors and markers are the forecasting results made by various models. We can see in Figure 2 that, in general, most models can produce similar forecasts to the real observations. In particular, during the period of 2000 to 2009, the growth rate of carbon emission experiences large fluctuations. We can see that those combination methods, such as BMA, BMS, DMA, and DMS, make more accurate predictions than others. In addition, we also find that the equal-weighted averaging model seems to offer too "mild" forecasts to follow the changing trend of real carbon emissions. Tables 3 and 4 report the results of forecasting errors and MCS test, respectively.
Table 3 shows the MSFE and MAFE of various models. Moreover, the $R^{2}$ of a Mincer-Zarnowitz regression is also reported in this table [64]. The Mincer-Zarnowitz approach is a regression of the real dependent variable against its fitted values produced by a forecasting model, which is also a commonly accepted approach to assess the forecast accuracy of a model. Like the meaning of ordinary adjusted $R^{2}$ in a multivariate regression, a larger $R^{2}$ of a Mincer-Zarnowitz regression indicates a better forecasting accuracy for a model.

Table 3 shows that, in general, dynamic combination (selection) methods, i.e., DMA, DMS, BMA, and BMS, 
TABLE 3: Results of loss functions for different forecasting models.

\begin{tabular}{lccc}
\hline & & Loss functions \\
Models & MSFE & MAFE & Mincer-Zarnowitz \\
\hline CC OLS & 0.00164 & 0.03140 & 0.20793 \\
TVP OLS & 0.00135 & 0.02807 & 0.32244 \\
Equal weighted & 0.00211 & 0.03553 & -0.02215 \\
BMA & 0.00117 & 0.02554 & 0.39684 \\
BMS & 0.00118 & 0.02579 & 0.38466 \\
DMA95 & 0.00117 & 0.02588 & $\mathbf{0 . 4 3 2 1 3}$ \\
DMS95 & 0.00119 & 0.02606 & 0.40760 \\
DMA99 & $\mathbf{0 . 0 0 1 1 6}$ & $\mathbf{0 . 0 2 5 5 2}$ & 0.40446 \\
DMS99 & 0.00118 & 0.02589 & 0.38941 \\
\hline
\end{tabular}

Note: the bold numbers in this table indicate the smallest MSFE and MAFE and the largest $R^{2}$ of a Mincer-Zarnowitz regression, respectively.

TABLE 4: Results of the MCS test.

\begin{tabular}{lccccccccccccc}
\hline & \multicolumn{1}{c}{ MSFE } \\
Models & $T_{R}$ & $T_{S Q}$ & $T_{\text {Max }}$ & $T_{Q}$ & $T_{F}$ & $T_{D}$ & $T_{R}$ & $T_{S Q}$ & $T_{\text {Max }}$ & $T_{Q}$ & $T_{F}$ & $T_{D}$ \\
\hline CC OLS & $\underline{0.0532}$ & 0.1836 & $\underline{0.0421}$ & $\underline{0.0190}$ & 0.1068 & $\underline{0.0557}$ & $\underline{0.0228}$ & 0.1081 & $\underline{0.0253}$ & $\underline{0.0107}$ & $\underline{0.0967}$ & $\underline{0.0185}$ \\
TVP OLS & 0.1092 & 0.5285 & 0.4836 & 0.4916 & 0.6097 & 0.4238 & 0.1343 & 0.4919 & 0.6017 & $\underline{0.0717}$ & 0.1814 & 0.4870 \\
Equal weighted & $\underline{0.0992}$ & 0.3116 & $\underline{0.0604}$ & $\underline{0.0006}$ & $\underline{0.0309}$ & $\underline{0.0683}$ & $\underline{0.0511}$ & 0.2200 & $\underline{0.0696}$ & $\underline{0.0094}$ & $\underline{0.0967}$ & $\underline{0.0336}$ \\
BMA & 0.9511 & 0.9700 & 0.9242 & 0.9280 & 0.9335 & 0.9495 & 0.9386 & 0.9386 & 0.9419 & 0.9701 & 0.9711 & 0.9419 \\
BMS & 0.9153 & 0.9700 & 0.9242 & 0.8302 & 0.8526 & 0.9495 & 0.9034 & 0.9277 & 0.8650 & 0.9701 & 0.9711 & 0.8950 \\
DMA95 & 0.9511 & 0.9700 & 0.9251 & 0.9280 & 0.9335 & 0.9495 & 0.9034 & 0.9099 & 0.8386 & 0.6742 & 0.6997 & 0.8950 \\
DMS95 & 0.9153 & 0.9664 & 0.9242 & 0.4916 & 0.6097 & 0.9495 & 0.8443 & 0.9099 & 0.8386 & 0.2473 & 0.3541 & 0.8950 \\
DMA99 & $\mathbf{1 . 0 0 0 0}$ & $\mathbf{1 . 0 0 0 0}$ & $\mathbf{1 . 0 0 0 0}$ & $\mathbf{1 . 0 0 0 0}$ & $\mathbf{1 . 0 0 0 0}$ & $\mathbf{1 . 0 0 0 0}$ & $\mathbf{1 . 0 0 0 0}$ & $\mathbf{1 . 0 0 0 0}$ & $\mathbf{1 . 0 0 0 0}$ & $\mathbf{1 . 0 0 0 0}$ & $\mathbf{1 . 0 0 0 0}$ & $\mathbf{1 . 0 0 0 0}$ \\
DMS99 & 0.9153 & 0.9700 & 0.9242 & 0.9280 & 0.9335 & 0.9495 & 0.8443 & 0.9099 & 0.8386 & 0.4055 & 0.4750 & 0.8950 \\
\hline
\end{tabular}

Notes: the underlined numbers indicate those $p$ values smaller than 0.1 , implying that the corresponding prediction models cannot survive the MCS tests. The bold numbers indicate $p$ values of 1.000 , showing that the corresponding prediction models perform better than all other competitive models. MSFE and MAFE denote mean squared forecast error and mean absolute forecast error, respectively.

produce close forecasting errors. In particular, under the MSFE and MAFE criteria, the DMA method with forgetting factors $\lambda=\alpha=0.99$ (DMA99) produces the smallest prediction errors of 0.00116 and 0.02552 , respectively. The equal-weighted averaging method, however, obtains the largest forecasting errors of 0.00211 and 0.03553 , respectively. With regard to Mincer-Zarnowitz regression, the DMA method with forgetting factors $\lambda=\alpha=0.95$ (DMA95) gets the largest $R^{2}$ of 0.43213 , implying again the superiority of DMA approach to individual CC or TVP models, as well as other combination methods.

In addition, to obtain a statistically robust conclusion about the forecasting accuracy of all the competitive models, we further conduct the MCS test on the forecasting results. Table 4 offers us a clearer picture of the performances of various prediction models. Firstly, no matter under MSFE or MAFE criteria with various statistics, the DMA method with forgetting factors $\lambda=\alpha=0.99$ (DMA99) can definitely survive with the largest $p$ values of 1.0 , revealing its dominance over other models. Secondly, we find that the CC OLS and equal-weighted averaging models cannot survive in the MCS tests under many statistical criteria with $p$ values smaller than 0.1 . This means that, on the one hand, constant coefficient (CC) model can rarely describe the true relationships between carbon emission in China and those commonly used explanatory variables and thus cannot provide accurate predictions for it. On the other hand, even if the equal-weighted averaging method is applied, it also lacks the ability to depict the time-varying contributions of different predictors in different time periods.

In summary, the empirical results in both Tables 3 and 4 supply strong evidence that the dynamic model averaging method (DMA) can produce better forecasting accuracy than other predictive models. This finding also verifies the rationality of considering both the TVP models and a model averaging (selection) procedure in forecasting the carbon emissions in China.

5.3. Contributions of Various Predictors in Forecasting China's Carbon Emission. In this section, we are to understand how much each predictor contributes to explaining the growth rate of carbon emission in China in the past few decades. This question is answered through a measurement called "inclusion probability," which measures the total weights obtained by one predictor through all the $K=2^{m}$ combinations of models in a DMA forecasting process. To be more formal, the inclusion probability for a predictor $x_{i}$ is the sum of the probabilities $\left(\pi_{(t \mid t t-n 1 q, h k)}\right)$ that a given predictor would be included in the forecasting model $k(k=1,2, \ldots, K)$ of DMA at time $t$. In this paper, as we have 15 predictors, the inclusion probability of predictor $x_{i}(i=1,2, \ldots, 15)$ will be a 
number summed through $K=2^{15}=32,768$ combinations of forecasting models. A predictor with a higher inclusion probability would be assigned more prediction weights, thus contributing more important predictive power.

Figure 3 presents the overall picture of the time-varying contributions (inclusion probabilities) of the 15 nonenergy predictors in forecasting growth rate of carbon emission in China. Firstly, we find that all the 15 indicators present a steady but distinct predictive ability for carbon emission in China over the past few decades. At the beginning of the prediction period, i.e., 1985 to 1994, the DMA method needs to calculate the historical performance of different model (predictor) combinations, and thus, the inclusion probabilities for different predictors show small dispersions with similar time-varying trends. In particular, at the first prediction time point in 1985, the DMA method assigns all the predictors with the same inclusion probability of 0.5 . As time goes by, however, with the different performances of various predictors, we can see that the inclusion probabilities begin to split up.

Secondly, predictors with major or minor contributions to predict carbon emissions in China are identified. It is clear that the proportion of industry production in GDP (IP) shows the greatest predictive power than others, while the growth rate of FDI to GDP (FDI) in China has the smallest forecasting ability. Interestingly, those Chinese household features, such as Engel's coefficient and household savings rate, are observed as the second and third important factors in explaining carbon emission in China. They provide more contributions than other factors from financial market, international trade, and technical progress sectors. That is to say, the household wealth and saving behavior are extremely important elements to determine China's family energy consumptions and thus have great predictive power for the carbon emission in China. Moreover, we also find that the proportion of value-added of the service sector to GDP (service added) has a large prediction ability to carbon emission in China. However, GDP per capita in China, an important index of macroeconomic development level, just makes moderate explanatory ability. Additionally, other factors except for those mentioned above, supply relatively small and similar forecasting power to carbon emission in China.

Finally, taking the time-varying trends for various inclusion probabilities into account, we get several interesting results as follows: first, although the IP index holds the largest forecasting weight among all the predictors, it clearly experiences a declining trend in its predictive power especially in recent years. Similarly, we also find the decreasing prediction power of the two household factors, i.e., Engel's coefficient and household saving since the year 2009. Then, it is worth mentioning that the proportion of value-added of the service sector to GDP (service added) presents not only a leading forecasting weight, but a continuous increasing prediction power in recent years. Notably, in 2016 and 2017, the inclusion probabilities assigned to service added becomes the second largest one among all the factors, implying its emerging status in explaining the carbon emission in China. In addition, other factors from financial markets, international trade, and technical progress have relatively small but increasing weights in recent years.

5.4. Robustness Checks of Model Forecasting Results. In this section, we utilize two alternative model evaluation methods to further check the forecasting performances of various predictive models. On the one hand, the forecasting directional accuracy of a model is also very important for investors and regulators' decision making. Degiannakis and Filis [65] opine that Direction-of-Change (DoC) is the core of market timing and portfolio trading strategies. Thus, following Degiannakis and Filis [65] and Zhang et al. [59], we adopt the Direction-of-Change (DoC) test as another model evaluation approach. In detail, DoC is a ratio that accounts for the accurate predictions to the total predictions in the direction of a forecasted variable by a model. Assuming that $p_{\mathrm{t}}$ is a dummy variable, it takes the value of 1 if the prediction model correctly forecasts the direction of carbon emission growth rate at time $t$, and 0 otherwise. It is defined as follows:

$$
p_{t}= \begin{cases}1, & \text { if } y_{t}>y_{t-1} \text { and } \hat{y}_{t}>y_{t-1}, \\ 1, & \text { if } y_{t}<y_{t-1} \text { and } \hat{y}_{t}<y_{t-1}, \\ 0, & \text { otherwise, }\end{cases}
$$

where $y_{t}$ and $\hat{y}_{t}$ are the actual growth rate of carbon emission and the forecasted growth rate of carbon emission made by a specific model, respectively. Mathematically, the DoC ratio is $1 / q \sum_{t=1}^{q} p_{t}$, where $q$ is the length of the out-of-sample forecasting period. A larger DoC rate, e.g., close to 1, indicates a better forecasting of directional changes by a model. In order to investigate the statistical significance of directional accuracy, we also use PT statistic proposed by Pesaran and Timmermann [66]. The null hypothesis of PT tests is that the DoC rate of a prediction model is smaller than or equal to the DoC rate of random walk forecasts.

Table 5 reveals similar results to those reported in Tables 3 and 4: DMA and DMS methods, as well as the BMA and BMS, show very close DoC rates from 0.742 to 0.774 , indicating that dynamic model combination (selection) methods can beat traditional TVP OLS and equal-weighted combination approaches in predicting the directional changes in the Chinese carbon emission growth rate. The constant coefficient (CC OLS) model, however, fails to pass the PT test with the lowest DoC rate of 0.548 .

In addition, we employ the out-of-sample $R^{2}\left(R_{\text {OOS }}^{2}\right)$ criterion proposed by Campbell and Thompson [67] to assess prediction accuracy. The out-of-sample $R^{2}$ of a forecasting model is defined as follows:

$$
R_{\mathrm{OOS}}^{2}=1-\frac{\sum_{k=1}^{q}\left(y_{k}-\hat{y}_{k}\right)^{2}}{\sum_{k=1}^{q}\left(y_{k}-\hat{y}_{k, \text { bench }}\right)^{2}},
$$

where $y_{k}, \hat{y}_{k}$, and $\hat{y}_{k \text {,bench }}$ are, respectively, the actual growth rate of carbon emission, the forecasted growth rate of carbon emission made by a specific model, and the 


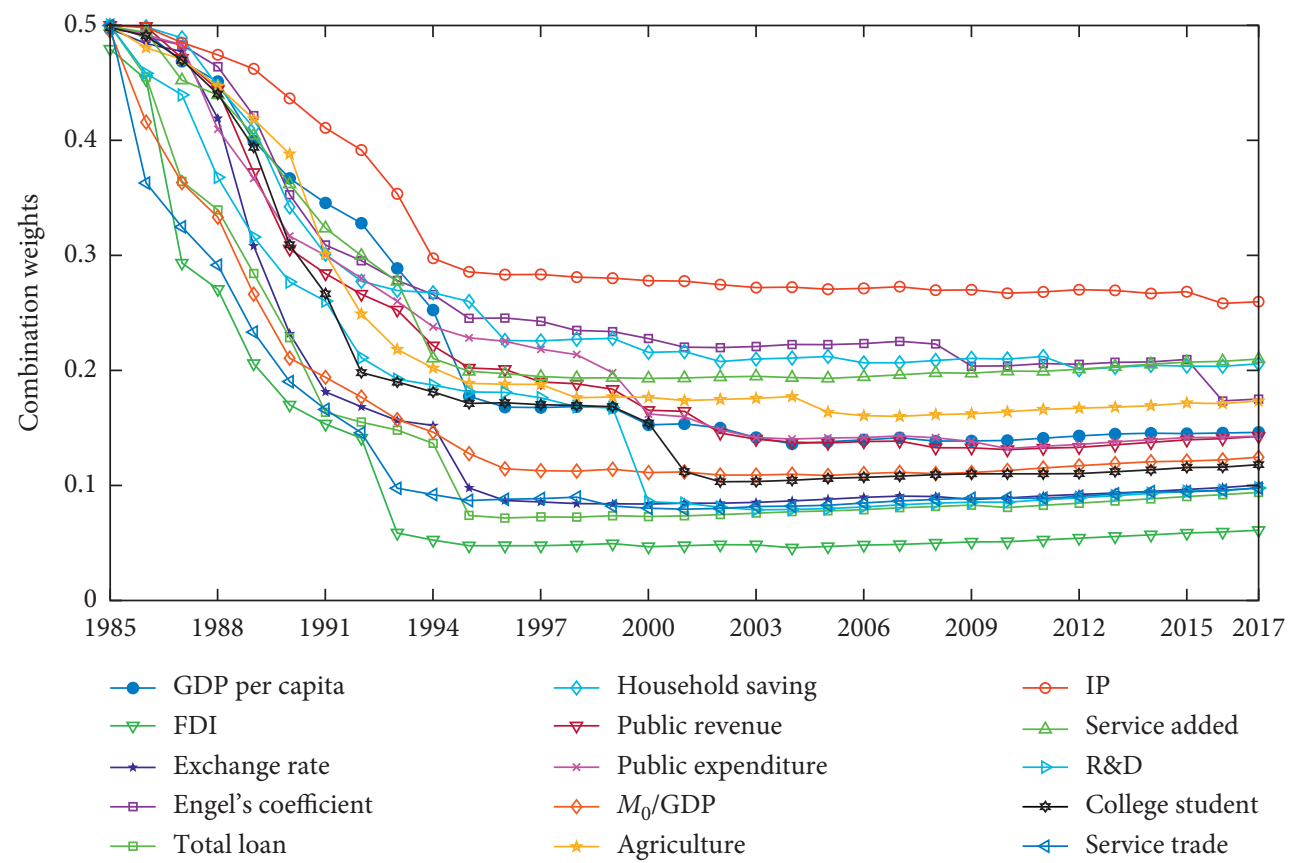

FIGURE 3: Inclusion probability (forecasting weights) for various nonenergy predictors.

TABle 5: Results of Direction-of-Change test.

\begin{tabular}{lccc}
\hline Models & DoC rate & PT statistic & $p$ value \\
\hline CC OLS & 0.548 & 0.568 & 0.285 \\
TVP OLS & $0.710^{* * *}$ & 2.368 & 0.009 \\
Equal weighted & $0.677^{* *}$ & 1.944 & 0.026 \\
BMA & $0.742^{* * *}$ & 2.771 & 0.003 \\
BMS & $0.774^{* * *}$ & 3.102 & 0.001 \\
DMA95 & $0.677^{* *}$ & 2.037 & 0.021 \\
DMS95 & $0.774^{* * *}$ & 3.102 & 0.001 \\
DMA99 & $0.742^{* * *}$ & 2.771 & 0.003 \\
DMS99 & $0.774^{* * *}$ & 3.102 & 0.001 \\
\hline
\end{tabular}

Notes: this table reports the Direction-of-Change (DoC) rates and the PT statistics of Pesaran and Timmermann [66] test for all forecasting approaches. Statistical significance for DoC rate is based on the $p$ values of the PT statistic. Symbols *, ${ }^{* *}$, and ${ }^{* * *}$ indicate the rejection of the null hypothesis at the $10 \%, 5 \%$, and $1 \%$ significance level, respectively.

forecasted growth rate of carbon emission made by the benchmark model on time $k$ and $q$ represents the length of the out-of-sample period. In this paper, we set CC OLS as the benchmark model and compare its performance with others. The $R_{\mathrm{OOS}}^{2}$ statistic evaluates the percent reduction in mean squared forecast error (MSFE) of a forecasting model relative to the benchmark. A positive value of $R_{\mathrm{OOS}}^{2}$ indicates a superior forecasting accuracy of a specific model to the benchmark. To estimate the significance of improvement in MSFE obtained by one model, we use the Clark and West [68] statistic, which implies the null hypothesis that the MSFE of the benchmark model is not larger than the MSFE of the interested model. The Clark and West [68] statistic is defined as follows:

$$
f_{t}=\left(y_{k}-\hat{y}_{k, \text { bench }}\right)^{2}-\left(y_{k}-\hat{y}_{k}\right)^{2}+\left(\hat{y}_{k, \text { bench }}-\hat{y}_{k}\right)^{2},
$$

TABle 6: Results of out-of-sample $R$-square test.

\begin{tabular}{lccc}
\hline Models & $R_{\text {OOS }}^{2}(\%)$ & MSFE-adjusted & $p$ value \\
\hline TVP OLS & $17.557^{* *}$ & 1.952 & 0.025 \\
Equal weighted & $-28.813^{*}$ & 1.455 & 0.073 \\
BMA & $28.796^{* *}$ & 2.323 & 0.010 \\
BMS & $27.980^{* * *}$ & 2.492 & 0.006 \\
DMA95 & $28.869^{* *}$ & 1.907 & 0.028 \\
DMS95 & $27.569^{* *}$ & 1.918 & 0.028 \\
DMA99 & $29.102^{* *}$ & 2.195 & 0.014 \\
DMS99 & $28.140^{* * *}$ & 2.350 & 0.009 \\
\hline
\end{tabular}

Notes: this table presents the out-of-sample prediction performance based on the out-of-sample $R^{2}$ test. The benchmark model is the CC OLS model. A positive value of out-of-sample $R^{2}$ implies that the forecasting model of interest has higher prediction accuracy than the benchmark model. Symbols ${ }^{*}, * *$, and ${ }^{* * *}$ indicate the rejection of the null hypothesis at the $10 \%, 5 \%$, and $1 \%$ significance level, respectively.

where $y_{k}, \hat{y}_{k}$, and $\hat{y}_{k \text {,bench }}$ are, respectively, the actual growth rate of carbon emission, the forecasted growth rate of carbon emission made by a specific model, and the forecasted growth rate of carbon emission made by the benchmark model on time $k$, respectively. The MSFE-adjusted statistic is the $t$-statistic from the regression of $f_{t}$ on a constant term. In addition, the $p$ value of the statistic can be obtained from the standard normal distribution [68].

Table 6 also shows quite similar outcomes presented in Tables 3 to 5. On the one hand, DMA and DMS methods, as well as the BMA and BMS, exhibit alike out-of-sample $R^{2}$ ranging from about $27 \%$ to $29 \%$, implying again the superior performances of dynamic model averaging (selection) models to the benchmark CC OLS. Among them, DMA99 and DMA95 are the best ones in all these methods. On the other hand, TVP OLS has better performance than the CC 
OLS, while the equal-weighted combination method fails to beat the benchmark model.

\section{Conclusions}

A large amount of literature pays close attention to those energy-related factors regarding their roles in explaining or forecasting carbon emission in China. It is no surprise that those energy-related factors, such as energy consumption and energy intensity, have significantly great impacts on the China's carbon emission. This paper, in contrast, focuses on the prediction power of nonenergy factors from macroeconomy, financial markets, household features, and technical progress sectors in China from a time-varying perspective. This research may offer us a new viewpoint to identify the underlying determinants of China's carbon emission and help the policymakers to introduce innovative and effective regulations to reduce carbon emission in China.

The major findings are listed as follows. Firstly, the explanatory power of each predictor changes significantly with time and no predictors always keep positive or negative effects on China's carbon emissions throughout the sample period. Secondly, the proportion of industry production in GDP (IP) presents the largest prediction power among all the 15 predictors, but with a decreasing weight in recent years. Similarly, two indices from household features, i.e., Engel's coefficient and household savings rate are observed as the second and third important factors in forecasting carbon emission in China. Thirdly, the proportion of valueadded of the service sector to GDP (service added) presents not only a leading forecasting weight, but a continuous increasing prediction power in recent years, especially since the year 2016. This result reveals that the development of service sector may bring significant changes in economic structure and energy consumption in China and thus gives more predictive power to future carbon emissions. Finally, in terms of forecasting methods, we find that individual constant coefficient (CC) and TVP models, as well as equalweighted averaging method, cannot provide satisfactory forecasting accuracy for the growth rate of carbon emission in China. However, the dynamic model averaging method (DMA) can dominate other individual and combination methods no matter in two simple evaluation criteria of MSFE and MAFE or other rigorous statistical tests.

The empirical results obtained in this paper have several important policy implications for the Chinese policymakers. For example, first of all, the time-varying positive or negative impacts of various predictors on China's carbon emission suggest that policymakers should not make fixed administrative policies to the factors that have effects on China's carbon emission considered in this paper. Then, both the decreasing prediction power of IP and the increasing weight of service added reveal that the Chinese government should persist in promoting the development of service sector in economy, especially those modern service industries, such as communication, information technology, finance, logistics, education, and medical care. The sustainable developments in these industries may be effective ways to reduce carbon emission in China. We think that the Chinese regulators do right efforts in this direction with the evidence that the IP/ GDP ratio decreases from about $44.6 \%$ in 1982 to about $40.4 \%$ in 2017 , while the service added/GDP ratio increases sharply from about $22.6 \%$ in 1982 to about $51.6 \%$ in 2017 . Finally, the household features measuring family wealth should also be concerned for their important roles in influencing the energy consumption behavior in Chinese families. The increasing wealth in China's family can accelerate more consumption in clean energy, i.e., solar, wind, and nuclear energy and thus reduce the carbon emission in China. Fortunately, in 2018, the Chinese government begins to massively cut taxes and administrative fees nationwide, which should have an optimistic impact on the reduction of China's carbon emission in the following years.

\section{Data Availability}

The data used in this paper are all confidential and are available by subscribers of the Wind database.

\section{Conflicts of Interest}

The authors declare no conflicts of interest.

\section{Authors' Contributions}

S.-Q. X. prepared the initial manuscript and the data collection. Y.-F. Z. made the empirical model estimations. X.-D. C. provided the pivotal idea of this research and the literature review. All authors have read and agreed to the published version of the manuscript.

\section{Acknowledgments}

This research was funded by the National Natural Science Foundation of China (71671145 and 71971191), Humanities and Social Science Fund of Ministry of Education of China (17YJA790015, 17XJA790002, 18YJC790132, and 18XJA790002), Science and Technology Innovation Team of Yunnan Provincial Universities (2019014), and Yunnan Fundamental Research Projects (202001AS070018).

\section{References}

[1] BP, Statistical Review of World Energy 2020, 2020, http://www. bp.com/statisticalreview, 69th edition.

[2] H. Iwata, K. Okada, and S. Samreth, "Empirical study on the determinants of $\mathrm{CO}_{2}$ emissions: evidence from OECD countries," Applied Economics, vol. 44, no. 27, pp. 3513-3519, 2012.

[3] N. Apergis and J. E. Payne, "Renewable energy, output, $\mathrm{CO}_{2}$ emissions, and fossil fuel prices in Central America: evidence from a nonlinear panel smooth transition vector error correction model," Energy Economics, vol. 42, pp. 226-232, 2014.

[4] C. F. Tang and B. W. Tan, "The impact of energy consumption, income and foreign direct investment on carbon dioxide emissions in Vietnam," Energy, vol. 79, pp. 447-454, 2015.

[5] E. M. Bildirici and T. Bakirtas, "The relationship among oil and coal consumption, carbon dioxide emissions, and 
economic growth in BRICTS countries," Journal of Renewable and Sustainable Energy, vol. 8, Article ID 045903, 2016.

[6] K. Dong, R. Sun, H. Jiang, and X. Zeng, " $\mathrm{CO}_{2}$ emissions, economic growth, and the environmental Kuznets curve in China: what roles can nuclear energy and renewable energy play?" Journal of Cleaner Production, vol. 196, pp. 51-63, 2018.

[7] S. A. Raza, N. Shah, and A. Sharif, "Time frequency relationship between energy consumption, economic growth and environmental degradation in the United States: evidence from transportation sector," Energy, vol. 173, pp. 706-720, 2019.

[8] Z. D. Shabani and R. Shahnazi, "Energy consumption, carbon dioxide emissions, information and communications technology, and gross domestic product in Iranian economic sectors: a panel causality analysis," Energy, vol. 169, pp. 1064-1078, 2019.

[9] A. Valadkhani, R. Smyth, and J. Nguyen, "Effects of primary energy consumption on $\mathrm{CO}_{2}$ emissions under optimal thresholds: evidence from sixty countries over the last half century," Energy Economics, vol. 80, pp. 680-690, 2019.

[10] X.-t. Jiang, Q. Wang, and R. Li, "Investigating factors affecting carbon emission in China and the USA: a perspective of stratified heterogeneity," Journal of Cleaner Production, vol. 199, pp. 85-92, 2018.

[11] Y. Zhang and S. Zhang, "The impacts of GDP, trade structure, exchange rate and FDI inflows on China's carbon emissions," Energy Policy, vol. 120, pp. 347-353, 2018.

[12] G. Koop and D. Korobilis, "Forecasting inflation using dynamic model averaging," International Economic Review, vol. 53, no. 3, pp. 867-886, 2012.

[13] D. E. Rapach and J. K. Strauss, "Differences in housing price forecastability across US states," International Journal of Forecasting, vol. 25, no. 2, pp. 351-372, 2009.

[14] L. Kristoufek, K. Janda, and D. Zilberman, "Correlations between biofuels and related commodities before and during the food crisis: a taxonomy perspective," Energy Economics, vol. 34, no. 5, pp. 1380-1391, 2012.

[15] E. Ghysels, A. Plazzi, R. Valkanov, and W. Torous, "Forecasting real estate prices," in Handbook of Economic Forecasting, G. Elliott and A. Timmermann, Eds., Elsevier, Amsterdam, Netherlands, 2013.

[16] O. Nneji, C. Brooks, and C. W. R. Ward, "House price dynamics and their reaction to macroeconomic changes," Economic Modelling, vol. 32, pp. 172-178, 2013.

[17] V. Plakandaras, R. Gupta, P. Gogas, and T. Papadimitriou, "Forecasting the U.S. real house price index," Economic Modelling, vol. 45, pp. 259-267, 2015.

[18] F. Collingro and M. Frenkel, "On the financial market impact of euro area monetary policy: a comparative study before and after the Global Financial Crisis," Global Finance Journal, 2019.

[19] M. Próchniak and B. Witkowski, "Time stability of the beta convergence among EU countries: Bayesian model averaging perspective," Economic Modelling, vol. 30, pp. 322-333, 2013.

[20] A. Vasnev, M. Skirtun, and L. Pauwels, "Forecasting monetary policy decisions in Australia: a forecast combinations approach," Journal of Forecasting, vol. 32, no. 2, pp. 151-166, 2013.

[21] G. Man, "Competition and the growth of nations: international evidence from Bayesian model averaging," Economic Modelling, vol. 51, pp. 491-501, 2015.

[22] J. Nowotarski, E. Raviv, S. Trück, and R. Weron, “An empirical comparison of alternative schemes for combining electricity spot price forecasts," Energy Economics, vol. 46, pp. 395-412, 2014.

[23] A. E. Raftery, M. Kárný, and P. Ettler, "Online prediction under model uncertainty via dynamic model averaging: application to a cold rolling mill," Technometrics, vol. 52, no. 1, pp. 52-66, 2010.

[24] Y. Wei and Y. Cao, "Forecasting house prices using dynamic model averaging approach: evidence from China," Economic Modelling, vol. 61, pp. 147-155, 2017.

[25] Y. Wei, J. Liu, X. Lai, and Y. Hu, "Which determinant is the most informative in forecasting crude oil market volatility: fundamental, speculation, or uncertainty?" Energy Economics, vol. 68, pp. 141-150, 2017.

[26] H. Naser and F. Alaali, "Can oil prices help predict US stock market returns? Evidence using a dynamic model averaging (DMA) approach," Empirical Economics, vol. 55, no. 4, pp. 1757-1777, 2018.

[27] V. Plakandaras, R. Gupta, and W.-K. Wong, "Point and density forecasts of oil returns: the role of geopolitical risks," Resources Policy, vol. 62, pp. 580-587, 2019.

[28] C. Zhang and Z. Tan, "The relationships between population factors and China's carbon emissions: does population aging matter?" Renewable and Sustainable Energy Reviews, vol. 65, pp. 1018-1025, 2016.

[29] Y. Guan, L. Kang, C. Shao, P. Wang, and M. Ju, "Measuring county-level heterogeneity of $\mathrm{CO}_{2}$ emissions attributed to energy consumption: a case study in Ningxia Hui Autonomous Region, China," Journal of Cleaner Production, vol. 142, pp. 3471-3481, 2017.

[30] L. Shi, J. Sun, J. Lin, and Y. Zhao, "Factor decomposition of carbon emissions in Chinese megacities," Journal of Environmental Sciences, vol. 75, pp. 209-215, 2019.

[31] X. Yao, D. Kou, S. Shao, X. Li, W. Wang, and C. Zhang, "Can urbanization process and carbon emission abatement be harmonious? new evidence from China," Environmental Impact Assessment Review, vol. 71, pp. 70-83, 2018.

[32] Q. Zhu and X. Peng, "The impacts of population change on carbon emissions in China during 1978-2008," Environmental Impact Assessment Review, vol. 36, pp. 1-8, 2012.

[33] S.-C. Ma, Y. Fan, and L. Feng, "An evaluation of government incentives for new energy vehicles in China focusing on vehicle purchasing restrictions," Energy Policy, vol. 110, pp. 609-618, 2017.

[34] H. Meng, X. Huang, H. Yang et al., "The influence of local officials' promotion incentives on carbon emission in Yangtze River Delta, China," Journal of Cleaner Production, vol. 213, pp. 1337-1345, 2019.

[35] Y. Wei, X. Zhu, Y. Li, T. Yao, and Y. Tao, "Influential factors of national and regional $\mathrm{CO}_{2}$ emission in China based on combined model of DPSIR and PLS-SEM," Journal of Cleaner Production, vol. 212, pp. 698-712, 2019.

[36] X. Ma, C. Wang, B. Dong et al., "Carbon emissions from energy consumption in China: its measurement and driving factors," Science of the Total Environment, vol. 648, pp. 1411-1420, 2019.

[37] J. Chen, Q. Shi, L. Shen, Y. Huang, and Y. Wu, "What makes the difference in construction carbon emissions between China and USA?" Sustainable Cities and Society, vol. 44, pp. 604-613, 2019.

[38] J. Kang, T. Zhao, N. Liu, X. Zhang, X. Xu, and T. Lin, “A multi-sectoral decomposition analysis of city-level greenhouse gas emissions: case study of Tianjin, China," Energy, vol. 68 , pp. 562-571, 2014. 
[39] Z. Wang and L. Yang, "Delinking indicators on regional industry development and carbon emissions: Beijing-TianjinHebei economic band case," Ecological Indicators, vol. 48, pp. 41-48, 2015.

[40] X.-W. Ma, Y. Ye, X.-Q. Shi, and L.-L. Zou, "Decoupling economic growth from $\mathrm{CO}_{2}$ emissions: a decomposition analysis of China's household energy consumption," $\mathrm{Ad}$ vances in Climate Change Research, vol. 7, no. 3, pp. 192-200, 2016.

[41] C. Shuai, X. Chen, Y. Wu, Y. Tan, Y. Zhang, and L. Shen, "Identifying the key impact factors of carbon emission in China: results from a largely expanded pool of potential impact factors," Journal of Cleaner Production, vol. 175, pp. 612-623, 2018.

[42] A. Jalil and M. Feridun, "The impact of growth, energy and financial development on the environment in China: a cointegration analysis," Energy Economics, vol. 33, no. 2, pp. 284-291, 2011.

[43] M. Liao and T. Wu, "The empirical analysis of the impact of industrial structure on carbon emissions," in Communication Systems and Information Technology, Springer, Berlin, Germany, 2011.

[44] H. Xu, Y. Li, and H. Huang, "Spatial research on the effect of financial structure on $\mathrm{CO}_{2}$ emission," Energy Procedia, vol. 118, pp. 179-183, 2017.

[45] Y.-J. Zhang, Y.-L. Peng, C.-Q. Ma, and B. Shen, "Can environmental innovation facilitate carbon emissions reduction? Evidence from China," Energy Policy, vol. 100, pp. 18-28, 2017.

[46] Z. Zhou, C. Liu, X. Zeng, Y. Jiang, and W. Liu, "Carbon emission performance evaluation and allocation in Chinese cities," Journal of Cleaner Production, vol. 172, pp. 1254-1272, 2018.

[47] J.-L. Mo, P. Agnolucci, M.-R. Jiang, and Y. Fan, “The impact of Chinese carbon emission trading scheme (ETS) on low carbon energy (LCE) investment," Energy Policy, vol. 89, pp. 271-283, 2016.

[48] R. J. R. Elliott, P. Sun, and S. Chen, "Energy intensity and foreign direct investment: a Chinese city-level study," Energy Economics, vol. 40, pp. 484-494, 2013.

[49] J. W. Lee, "The contribution of foreign direct investment to clean energy use, carbon emissions and economic growth," Energy Policy, vol. 55, pp. 483-489, 2013.

[50] A. Omri, S. Daly, C. Rault, and A. Chaibi, "Financial development, environmental quality, trade and economic growth: what causes what in MENA countries," Energy Economics, vol. 48, pp. 242-252, 2015.

[51] J. A. Frankel and D. Romer, "Does trade cause growth?" American Economic Review, vol. 89, no. 3, pp. 379-399, 1999.

[52] P. Sadorsky, "Financial development and energy consumption in Central and Eastern European frontier economies," Energy Policy, vol. 39, no. 2, pp. 999-1006, 2011.

[53] S. Iamsiraroj, "The foreign direct investment-economic growth nexus," International Review of Economics \& Finance, vol. 42, pp. 116-133, 2016.

[54] H. Nasir, S. Majeed, and A. Aleem, "Does financial development leads economic growth? Evidence from emerging asian markets," Asian Economic and Financial Review, vol. 8, no. 5, pp. 599-617, 2018.

[55] Y.-J. Zhang, "The impact of financial development on carbon emissions: an empirical analysis in China," Energy Policy, vol. 39, no. 4, pp. 2197-2203, 2011.
[56] G. E. Primiceri, "Time varying structural vector autoregressions and monetary policy," The Review of Economic Studies, vol. 72, no. 3, pp. 821-852, 2005.

[57] G. Koop, R. Leon-Gonzalez, and R. W. Strachan, "On the evolution of the monetary policy transmission mechanism," Journal of Economic Dynamics and Control, vol. 33, no. 4, pp. 997-1017, 2009.

[58] P. R. Hansen, A. Lunde, and J. M. Nason, "The model confidence set," Econometrica, vol. 79, pp. 453-497, 2011.

[59] Y. Zhang, Y. Wei, Y. Zhang, and D. Jin, "Forecasting oil price volatility: forecast combination versus shrinkage method," Energy Economics, vol. 80, pp. 423-433, 2019.

[60] F. X. Diebold and R. S. Mariano, "Comparing predictive accuracy," Journal of Business \& Economic Statistics, vol. 13, no. 3, pp. 253-263, 1995.

[61] K. D. West, "Asymptotic inference about predictive ability," Econometrica, vol. 64, no. 5, pp. 1067-1084, 1996.

[62] H. White, "A reality check for data snooping," Econometrica, vol. 68, no. 5, pp. 1097-1126, 2000.

[63] P. R. Hansen, "A test for superior predictive ability," Journal of Business \& Economic Statistics, vol. 23, no. 4, pp. 365-380, 2005.

[64] M. L. Higgins and S. Mishra, "Testing forecast rationality under asymmetric loss with the Mincer-Zarnowitz regression," Journal of Quantitative Economics, vol. 7, pp. 59-72, 2009.

[65] S. Degiannakis and G. Filis, "Forecasting oil price realized volatility using information channels from other asset classes," Journal of International Money and Finance, vol. 76, pp. 28-49, 2017.

[66] M. H. Pesaran and A. Timmermann, "A simple nonparametric test of predictive performance," Journal of Business \& Economic Statistics, vol. 10, no. 4, pp. 461-465, 1992.

[67] J. Y. Campbell and S. B. Thompson, "Predicting excess stock returns out of sample: can anything beat the historical average?" Review of Financial Studies, vol. 21, no. 4, pp. 1509-1531, 2008.

[68] T. E. Clark and K. D. West, "Approximately normal tests for equal predictive accuracy in nested models," Journal of Econometrics, vol. 138, no. 1, pp. 291-311, 2007. 